\title{
Genome-Wide Analysis of Targets for Post-Transcriptional Regulation by Rsm Proteins in Pseudomonas putida
}

\author{
Óscar Huertas-Rosales ${ }^{1}$, Manuel Romero ${ }^{2}$, Kok-Gan Chan ${ }^{3,4}$, Kar-Wai Hong ${ }^{3,4}$, \\ Miguel Cámara ${ }^{2}$, Stephan Heeb ${ }^{2}$, Laura Barrientos-Moreno ${ }^{1,2}$, \\ María Antonia Molina-Henares ${ }^{1}$, María L. Travieso ${ }^{1}$, Maria Isabel Ramos-González ${ }^{1}$ and \\ Manuel Espinosa-Urgel ${ }^{1 *}$
}

${ }^{1}$ Department of Environmental Protection, Estación Experimental del Zaidín, CSIC, Granada, Spain, ${ }^{2}$ National Biofilms Innovation Centre, Biodiscovery Institute and School of Life Sciences, University of Nottingham, Nottingham, United Kingdom, ${ }^{3}$ Division of Genetics and Molecular Biology, Institute of Biological Sciences, Faculty of Science, University of Malaya, Kuala Lumpur, Malaysia, ${ }^{4}$ International Genome Centre, Jiangsu University, Zhenjiang, China

OPEN ACCESS

Edited by:

Chew Chieng Yeo, Sultan Zainal Abidin University, Malaysia

Reviewed by: Frederic Allain,

ETH Zürich, Switzerland

Lydia Contreras,

University of Texas at Austin,

United States

*Correspondence:

Manuel Espinosa-Urgel manuel.espinosa@eez.csic.es

Specialty section: This article was submitted to

Molecular Recognition,

a section of the journal

Frontiers in Molecular Biosciences

Received: 30 October 2020 Accepted: 21 January 2021 Published: 22 February 2021

Citation: Huertas-Rosales Ó, Romero $M$, Chan K-G, Hong K-W, Cámara M,

Heeb S, Barrientos-Moreno L, Molina-Henares MA, Travieso ML,

Ramos-González MI and Espinosa-Urgel M (2021) GenomeWide Analysis of Targets for PostTranscriptional Regulation by Rsm Proteins in Pseudomonas putida.

Front. Mol. Biosci. 8:624061. doi: 10.3389/fmolb.2021.624061
Post-transcriptional regulation is an important step in the control of bacterial gene expression in response to environmental and cellular signals. Pseudomonas putida KT2440 harbors three known members of the CsrA/RsmA family of posttranscriptional regulators: RsmA, RsmE and Rsml. We have carried out a global analysis to identify RNA sequences bound in vivo by each of these proteins. Affinity purification and sequencing of RNA molecules associated with Rsm proteins were used to discover direct binding targets, corresponding to 437 unique RNA molecules, 75 of them being common to the three proteins. Relevant targets include genes encoding proteins involved in signal transduction and regulation, metabolism, transport and secretion, stress responses, and the turnover of the intracellular second messenger c-di-GMP. To our knowledge, this is the first combined global analysis in a bacterium harboring three Rsm homologs. It offers a broad overview of the network of processes subjected to this type of regulation and opens the way to define what are the sequence and structure determinants that define common or differential recognition of specific RNA molecules by these proteins.

Keywords: RNA-binding proteins, global regulation, biofilm, rhizosphere, amino acid metabolism, c-di-GMP signaling

\section{INTRODUCTION}

By coordinating the expression of a large number of genes, global regulatory networks allow bacteria to adjust their physiology according to environmental stimuli, changes in their lifestyle, or in nutritional status (Ishihama, 2010; Coggan and Wolfgang, 2012; Shis et al., 2018). Transcriptional regulators and sigma factors influencing the expression of different sets of bacterial genes have been widely studied for decades, starting shortly after the postulates of Jacob and Monod on operons, operators and messenger RNA were put forward (Jacob and Monod, 1961). A second instance of protein expression regulation, namely post-transcriptional modulation affecting mRNA stability, structure or translation, mediated by proteins or small non-coding RNAs, has gained increasing attention in the past 2 decades, but is still less well studied (Romeo et al., 2013; Van Assche et al., 2015; Hör et al., 2018). Among the post-transcriptional regulators identified in prokaryotes, the CsrA/RsmA family of proteins seems to be widely conserved in many bacteria and, in some cases, 
more than one member of this family are present in a single species (Reimmann et al., 2005; Morris et al., 2013; HuertasRosales et al., 2016; Ferreiro et al., 2018). These small RNAbinding proteins generally function as negative effectors of translation by binding to the $5^{\prime}$ untranslated region of target mRNAs, close to or overlapping with the ribosome binding site (Baker et al., 2007; Yakhnin et al., 2007), or by causing premature transcription termination through alterations of the RNA structure that lead to the exposure of a Rho binding site (Figueroa-Bossi et al., 2014). However, they can also influence mRNA stability in a positive way, for example, by masking RNase E cleavage sites (Yakhnin et al., 2013). CsrA/RsmA proteins can interact with two RNA motifs, with a strong preference for $5^{\prime}$ RUACARGGAUGU- $3^{\prime}$ consensus sequences located in the loops of short RNA hairpins (Dubey et al., 2005; Duss et al., 2014). Small non-coding RNAs (sRNA) containing multiple binding motifs play an opposing regulatory role by sequestering the CsrA/ RsmA proteins, thus limiting their access to target mRNAs (Romeo, 1998; Kay et al., 2005; Sonnleitner and Haas, 2011; Janssen et al., 2018). In Pseudomonas, expression of these regulatory RNAs is controlled by the two-component system GacS/GacA (Brencic et al., 2009), in response to as yet not welldefined signal(s).

CsrA/RsmA proteins play a global role in modulating gene expression (Romeo, 1998; Lawhon et al., 2003; Brencic and Lory, 2009; Romeo et al., 2013; Romero et al., 2018). The functions identified as being under this type of regulation in different bacteria include carbohydrate metabolism and storage (Sabnis et al., 1995; Yang et al., 1996; Pannuri et al., 2016), synthesis of flagellar components (Yakhnin et al., 2007, Yakhnin et al., 2013), the production of secondary metabolites (Sonnleitner and Haas, 2011; Morris et al., 2013), quorum sensing signaling (Lenz et al., 2005), or the expression of virulence factors (Heroven et al., 2012; Sterzenbach et al., 2013; Vakulskas et al., 2015; Ferreiro et al., 2018). Global analyses have been done in bacteria harboring one CsrA/RsmA family protein to identify elements in the signaling and regulatory network associated to them (Lawhon et al., 2003; Sowa et al., 2017) or to othologous elements (Romero et al., 2018).

In the plant-root colonizing, beneficial bacterium Pseudomonas putida KT2440, three genes have been identified that encode post-transcriptional regulators belonging to the CsrA/RsmA family. These proteins (RsmA, RsmE and RsmI), have opposing effects on surface motility and biofilm formation; deletion of the three genes abolishes swarming motility and stimulates bacterial attachment and biofilm formation, although the biofilms formed by a triple rsm mutant are more labile and easily dispersed than wild type biofilms (HuertasRosales et al., 2016). These alterations are associated with changes in the expression of some components of the extracellular matrix of biofilms (Huertas-Rosales et al., 2016) and with increased levels of the intracellular second messenger cyclic diguanylate (c-di-GMP) (Huertas-Rosales et al., 2017). The three proteins were found to bind specific motifs in the leader sequence and translation initiation region of the mRNA of $c f c R$ (Huertas-Rosales et al., 2017), which encodes a response regulator with diguanylate cyclase activity (Matilla et al., 2011; RamosGonzález et al., 2016). Although the binding affinity was different for each Rsm protein, deletion of any single one of the three genes had no significant influence on expression of $c f c R$ (HuertasRosales et al., 2017), indicating the existence of some functional redundancy between RsmA, RsmE and RsmI. Based on sequence similarity with related strains, the putative antagonistic sRNAs RsmY and RsmZ could also be identified in KT2440 (Huertas-Rosales et al., 2016). Still, little is known about the binding specificities of these proteins in P. putida.

To further understand the importance of these proteins in signal transduction and regulation of global gene expression in $P$. putida, we have used a high-throughput approach to identify RNA sequences bound by Rsm proteins. Our data indicate that a significant number of genes are susceptible of being modulated at the post-transcriptional level by these proteins, and support the existence of a certain degree of functional overlap between the three Rsm homologs. This approach has enabled us to gain new insights into the biological function of these post-transcriptional regulators in $P$. putida, including their role in some metabolic processes and bacterial fitness in the plant root environment.

\section{MATERIALS AND METHODS}

\section{Bacterial Strains, Culture Media and Growth Conditions}

The bacterial strains, plasmids and oligonucleotides used in this study are listed in Table 1. Pseudomonas putida KT2440 is a plasmid-free derivative of $P$. putida mt-2 (Regenhardt et al., 2002). Pseudomonas putida strains were grown at $30^{\circ} \mathrm{C}$, in rich LB medium (Lennox, 1955), M9 or M8 defined medium (Sambrook and Russell, 2001) supplemented with $1 \mathrm{mM} \mathrm{MgSO}_{4}, 6 \mathrm{mg} / \mathrm{L}$ ammonium ferric citrate and trace metals as described previously (Yousef-Coronado et al., 2008). Unless otherwise indicated, glucose $(20 \mathrm{mM})$ or sodium citrate (15 mM) were used as carbon sources. Escherichia coli strains were grown at $37^{\circ} \mathrm{C}$ in $\mathrm{LB}$. When appropriate, antibiotics were added to the medium at the following final concentrations $(\mu \mathrm{g} / \mathrm{ml})$ : ampicillin (Ap) 100; kanamycin (Km) 25; streptomycin (Sm) 50 (E. coli) or 100 (P. putida); (Gm) gentamycin 50; tetracycline (Tc) 10 or 20 . Cell growth was followed by measuring optical density at $660 \mathrm{~nm}$ $\left(\mathrm{OD}_{660}\right)$.

\section{DNA Techniques}

Digestion with restriction enzymes, dephosphorylation, ligation and electrophoresis were carried out using standard methods (Ausubel et al., 1987; Sambrook and Russell, 2001) and following manufacturers' instructions. Plasmid DNA isolation and recovery of DNA fragments from agarose gels were carried out using QIAGEN miniprep and gel extraction kits, respectively. Competent cells were prepared using calcium chloride, and transformations were performed using standard protocols (Sambrook and Russell, 2001). Electrotransformation of freshly plated Pseudomonas cells was performed as previously described (Choi et al., 2006).

\section{Triparental Conjugations}

Transfer of plasmids from $E$. coli to $P$. putida strains was performed by triparental matings using as a helper for RP4 
TABLE 1 | Bacterial strains, plasmids and oligonucleotides used in this work.

\begin{tabular}{|c|c|c|}
\hline Strains & Genotype/relevant characteristics & References/source \\
\hline \multicolumn{3}{|l|}{ P. putida } \\
\hline KT2440 & Wild-type, pWWO-free derivative of $P$. putida mt-2 & PRCC $^{a}$ \\
\hline$\Delta \mathrm{l}$ & Null rsml derivative of KT2440 & 10 \\
\hline$\Delta \mathrm{E}$ & Null rsmE derivative of KT2440 & 10 \\
\hline$\Delta \mathrm{A}$ & Null rsmA derivative of KT2440 & 10 \\
\hline$\Delta \mathrm{IE}$ & Double null rsml, rsmE derivative of KT2440 & 10 \\
\hline$\Delta \mathrm{IA}$ & Double null rsml, rsmA derivative of KT2440 & 10 \\
\hline$\Delta \mathrm{EA}$ & Double null rsmE, rsmA derivative of KT2440 & 10 \\
\hline$\triangle \mathrm{IEA}$ & Triple null rsml, rsmE, rsmA derivative of KT2440 & 10 \\
\hline KT2440-miniTn7-Km & $\mathrm{Km}^{\mathrm{R}}$, miniTn7Km-tagged derivative of KT2440 & This work \\
\hline KT2440-miniTn7-Sm & $\mathrm{Sm}^{\mathrm{R}}$, miniTn7Sm-tagged derivative of KT2440 & This work \\
\hline$\Delta \mathrm{A}-\mathrm{miniTn} 7-\mathrm{Sm}$ & $\mathrm{Sm}^{\mathrm{R}}$, miniTn7Sm-tagged derivative of $\Delta r s m A$ & This work \\
\hline$\Delta \mathrm{E}-\mathrm{miniTn} 7-\mathrm{Sm}$ & $\mathrm{Sm}^{\mathrm{R}}$, miniTn7Sm-tagged derivative of $\Delta r s m E$ & This work \\
\hline$\Delta \mathrm{l}-\mathrm{miniTn} 7-\mathrm{Sm}$ & $\mathrm{Sm}^{\mathrm{R}}$, miniTn7Sm-tagged derivative of $\Delta r s m \mathrm{l}$ & This work \\
\hline$\Delta$ EA-miniTn7-Sm & $\mathrm{Sm}^{\mathrm{R}}$, miniTn7Sm-tagged derivative of $\Delta r s m E A$ & This work \\
\hline$\Delta \mathrm{IA}-\mathrm{miniTn} 7-\mathrm{Sm}$ & $\mathrm{Sm}^{\mathrm{R}}$, miniTn7Sm-tagged derivative of $\Delta r s m I A$ & This work \\
\hline$\Delta \mathrm{IE}-\mathrm{miniTh} 7-\mathrm{Sm}$ & $\mathrm{Sm}^{\mathrm{R}}$, miniTn7Sm-tagged derivative of $\Delta r S m I E$ & This work \\
\hline$\Delta \mathrm{IEA}-\mathrm{miniTn} 7-\mathrm{Sm}$ & $\mathrm{Sm}^{\mathrm{R}}$, miniTn7Sm-tagged derivative of $\triangle r S m I E A$ & This work \\
\hline \multicolumn{3}{|l|}{ E. coli } \\
\hline AKN63 (pBK-miniTn7- $\Omega S m 1)$ & $A p^{R}, S^{R}$, strain for delivery of miniTn7Sm & 42 \\
\hline Pir1 (pUC18R6KT-mini-Tn7Km) & $A p^{R}, \mathrm{Km}^{\mathrm{R}}$, strain for delivery of miniTn7Km & Addgene \\
\hline SM10 גpir (pUX-BF13) & $A p^{R}, \mathrm{RP} 4$ transfer functions and miniTn7 transposase helper & 42 \\
\hline $\mathrm{DH} 5 a(\mathrm{pRK} 600)$ & $\mathrm{Cm}^{\mathrm{R}}$, helper for conjugation & PRCC \\
\hline \multicolumn{3}{|l|}{ Plasmids } \\
\hline pME6032-rsmA & $\mathrm{Tc}^{\mathrm{R}}$, derivative of pME6032 for expression of $\mathrm{RsmA}^{-H i s_{6}}$ & 10 \\
\hline pME6032-rsmE & $\mathrm{Tc}^{\mathrm{R}}$, derivative of pME6032 for expression of RsmE-His 6 & 10 \\
\hline pME6032-rsml & $\mathrm{Tc}^{\mathrm{R}}$, derivative of pME6032 for expression of Rsml-His ${ }_{6}$ & 10 \\
\hline Oligonucleotides & Sequence $\left(5^{\prime} \rightarrow 3^{\prime}\right) \mathrm{b}$ & Use \\
\hline PT7rpoSFw & ППTCTGCAGTAATACGACTCACTATAGGCTCAAGCGCTGCCAGGGA & EMSA, rpoS amplification \\
\hline PrpoSFTRv & AAAAAAAACССССССССПТАСТGAGAGCСАТTG & EMSA, rpoS amplification \\
\hline PT7rsmYFw & 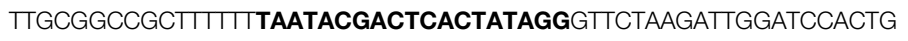 & EMSA, rsmY amplification \\
\hline PrsmYFTRv & AAAAGCGGCCGCAAAAAAAACCCCCCCCCGCCGAAGCGGGGTITCCAG & EMSA, rsmY amplification \\
\hline
\end{tabular}

${ }^{a} P$ seudomonas Reference Culture Collection (http://artemisa.eez.csic.es/prcc/).

${ }^{b}$ Restriction sites are underlined, inserted T7 polymerase promoter is indicated in bold and sequences used to hybridize with ATTO700-labelled DNA oligonucleotide are highlighted in gray.

transfer functions E. coli (pRK600) or SM10 גpir (pUX-BF13), the latter when miniTn7 transposase was required for intergenic site-specific insertion of miniTn7 derivatives near $g \operatorname{lm} S$ (Koch et al., 2001), used to tag the wild type and each rsm mutant (Table 1) for rhizosphere assays (see below). For each strain, cells were collected from $0.5 \mathrm{ml}$ of overnight LB cultures via centrifugation, then washed and suspended in $50 \mu \mathrm{L}$ of fresh LB, and finally spotted on nitrocellulose filters $(0.22 \mu \mathrm{m}$ pore diameter) on LB-agar plates. After overnight incubation at $30^{\circ} \mathrm{C}$, cells were scraped off from the mating filter and suspended in $2 \mathrm{ml}$ of $\mathrm{M} 9$, and serial dilutions were plated on selective medium (M9 with citrate and the appropriate antibiotics) to select exconjugants and counter-select donor, helper, and recipient strains.

\section{Purification of Total RNA and RNA from Rsm-RNA Complexes}

Previously constructed derivatives of expression vector pME6032 harboring each rsm gene (Huertas-Rosales et al., 2016) were used to express His-tagged Rsm proteins in P. putida KT2440. Overnight cultures $(10 \mathrm{ml})$ of wild type KT2440 harboring each construct were inoculated in $500 \mathrm{ml}$ of LB medium.
Three biological replicates were run in parallel. Cultures were incubated at $30^{\circ} \mathrm{C}$ under shaking until an $\mathrm{OD}_{660}$ of 0.8 was reached. At that point, expression of each His-tagged-Rsm protein was induced by the addition of IPTG to a final concentration of $0.5 \mathrm{mM}$. Cultures were allowed to grow for six additional hours. Aliquots of $1.5 \mathrm{ml}$ were then harvested by centrifugation, instantly frozen with liquid nitrogen and stored at $-80^{\circ} \mathrm{C}$ for total RNA purification. Cells from the remaining culture volume were also harvested and pellets were stored at $-80^{\circ} \mathrm{C}$ until use. His-tagged Rsm-RNA complexes were isolated using Ni-NTA Fast Start purification kit (Qiagen). Three replicate extractions were done for each culture replica. Elution aliquots were analyzed by SDS-PAGE.

Total RNA and RNA from Rsm-RNA complex was extracted using RNA isolation kit (Macherey-Nagel) following the manufacturer's instructions. RNA samples were subsequently treated with RNase-free DNase I (Turbo DNA-free kit, Ambion) to remove DNA traces, as specified by the supplier. Total RNA quality was assessed using Agilent RNA 6000 Nano Kit (Agilent Technologies) in the Agilent 2100 Bioanalyzer. RNA concentration was measured using Qubit RNA BR assay kit (Life Technologies). $1 \mu \mathrm{g}$ of RNA was used for rRNA depletion using Ribo-Zero rRNA Removal Kit (Illumina). One of the biological 
replicates of RsmA and one of RsmI did not meet the required quality and quantity standards and were not used in further analysis.

\section{Generation of c-DNA Libraries and Sequencing}

The generation of cDNA libraries was carried out using NEBNext Ultra Directional RNA Library Prep kit for Illumina (NEB). Dual Index Primers Set one was used to generate bar-coded multiplex libraries (NEB). Library QC was performed using bioanalyser HS kit (Agilent biotechnologies). cDNA libraries were quantified using qPCR (Kapa Biosystems). Libraries were pooled at the desired concentrations, denatured and loaded for sequencing according to manufacturer's instructions. Sequencing was performed on the Illumina MiSeq Benchtop Sequencer to generate $2 \times 75 \mathrm{bp}$ reads. The number of reads obtained ensured a minimum of $76 \times$ coverage of the whole genome for control RNA and a minimum of $60 \times$ coverage for Rsmbound RNA.

\section{Bioinformatic Analysis}

Filtered reads were aligned to reference genome $P$. putida KT2440 (GenBank; RefSeq NC_002947.3) with Bowtie v2 (Langmead et al., 2009). Alignment. sam file was analyzed using MACS v14 to identify and evaluate the significance of reads-enriched regions in the genome, the output being one file containing the peak chromosome coordinates, and one containing the genome coordinates, summit, $p$-value, fold_enrichment and false discovery rate (FDR) of each peak (Zhang et al., 2008). The average number of tags in the control samples after filtering was approximately 2,220,000 (RsmA), 1,420,000 (RsmE), and 1,654,000 (RsmI); the average number of tags in the Rsm-bound samples after filtering was approximately $1,302,000$ (RsmA), 550,000 (RsmE), and 1,054,000 (RsmI). Only those peaks present in the three technical replicates were considered. Identity and annotation of the targets above the cut-off values were further validated by individually inspecting the corresponding chromosomal regions in the Pseudomonas genome database (www.pseudomonas.com; Winsor et al., 2016).

\section{EMSA Analysis of in vitro RNA-Protein Binding}

For purification of Rsm proteins, overnight cultures $(10 \mathrm{ml})$ of $P$. putida KT2440 harboring plasmids pME6032-rsmA, pME6032rsmE, and pME6032-rsmI (Huertas-Rosales et al., 2016) were used to inoculate $490 \mathrm{ml}$ fresh LB medium supplied with Tc. Cultures were grown at $30^{\circ} \mathrm{C}$ and $200 \mathrm{rpm}$ until reaching an $\mathrm{OD}_{660}$ of 0.8 . At this point, IPTG $(0.5 \mathrm{mM})$ was added to induce the expression of the proteins. After $6 \mathrm{~h}$ of further growth, cells were harvested by centrifugation and pellets subsequently stored at $-80^{\circ} \mathrm{C}$. Protein purification was carried out using QIAexpress Ni-NTA Fast Start Kit (Qiagen), following the manufacturers' instructions.
Electrophoretic mobility shift assays (EMSA) were carried out following a method described previously (Romero et al., 2018). DNA templates corresponding to the target gene sequences were amplified by PCR using primers that incorporated a $\mathrm{T} 7$ promoter at the $5^{\prime}$ end and a 17-nt extension at the $3^{\prime}$ end (Table 1). The purified PCR product was used for RNA synthesis in vitro using the MAXIscript T7 kit (Life Technologies). The RNA obtained was visualized by hybridization of an ATTO700-labeled DNA primer to the $3^{\prime}$ extension of the RNA. Rsm proteins were incubated with target gene RNA ( 5 or $10 \mathrm{nM}$ ) in $1 \times$ binding buffer [25]. Binding in the absence or presence of unlabeled competitor RNA (100-fold excess) was carried out for $30 \mathrm{~min}$ at $30^{\circ} \mathrm{C}$. Then Bromophenol Blue was added $(0.01 \%$, wt $/ \mathrm{vol})$ before electrophoresis on $6 \% \quad(\mathrm{w} / \mathrm{v})$ non-denaturing polyacrylamide TBE gel at $4^{\circ} \mathrm{C}$. Imaging was performed using a 9201 Odyssey Imaging System (LI-COR Biosciences).

\section{Growth with Different Carbon and Nitrogen Sources}

BIOLOG plates (Biolog Inc. Hayward, CA, USA) were used for initial assessment of growth of KT2440 and the triple $\triangle r s m I E A$ mutant with different nitrogen and carbon sources. Cultures grown overnight at $30^{\circ} \mathrm{C}$ in $\mathrm{M} 9$ minimal medium with glucose as carbon source were used for inoculation in the plates at an initial $\mathrm{OD}_{660}$ of 0.05 . Turbidity was measured at different times over $24 \mathrm{~h}$ in a Tecan Sunrise microplate reader. Further experiments were done in 96-well plates using M9 or M8 with the indicated carbon or nitrogen sources, at a final concentration of $5 \mathrm{mM}$. Growth was followed for $24 \mathrm{~h}$ at $3^{\circ} \mathrm{C}$ with continuous shaking in a Bioscreen apparatus $\mathrm{C}$ MBR equipped with a wide band filter $(420-580 \mathrm{~nm})$.

\section{Competitive Root Colonization Assays}

Surface sterilization, germination of corn seeds, and bacterial inoculation of the seedlings were performed as described previously (Ramos-González et al., 2013). Briefly, at least six two-days old seedlings were inoculated with a 1:1 mix $(\sim 5 \times$ $10^{5} \mathrm{CFU} /$ strain) of KT2440Tn7-Km, as the wild type, and the wild type or mutant derivatives tagged with miniTn7Sm by triparental conjugation as described above. Inocula sizes were monitored by plating on LB-agar supplied with kanamycin or streptomycin. After 7 days, bacteria were recovered from the rhizosphere or the root tip as specified (Ramos-González et al., 2013) and the number of cells of each strain in the population was estimated by plating on LB-agar supplied with kanamycin or streptomycin. Data are presented as the index of colonization fitness (Ramos-González et al., 2013). SigmaStat software package (Systat software) was used for statistical analysis. The data were compared using Student's $t$-test for independent samples $(p<0.05)$.

\section{Data-Availability}

Raw and processed data files have been deposited in the Gene Expression Omnibus Database (www.ncbi.nlm.nih.gov/geo/) and are available under accession number GSE154204. 
TABLE 2 | Summary of the high throughput data analysis of Rsm targets in P. putida KT2440.

\begin{tabular}{|c|c|c|c|c|c|c|c|c|}
\hline $\begin{array}{l}\text { Biological } \\
\text { replica }\end{array}$ & $\begin{array}{c}\text { total } \\
\text { peaks }\end{array}$ & $\begin{array}{l}\text { CI } 95^{\mathrm{a}} \text { fold enrichment } \\
\text { (lower limit) }\end{array}$ & $\begin{array}{l}\text { Cut-off } \\
\text { value }\end{array}$ & $\begin{array}{c}\text { Cl } 95-10 \times \text { log } \\
(P \text { val) (lower limit) }\end{array}$ & $\begin{array}{l}\text { Cut-off } \\
\text { value }\end{array}$ & $\begin{array}{l}\text { peaks above } \\
\text { cut-off values }\end{array}$ & $\begin{array}{c}\text { peaks in all } \\
\text { biological replicas }\end{array}$ & $\begin{array}{l}\text { unique RNA } \\
\text { targets }^{b}\end{array}$ \\
\hline RsmA1 & & & 2.15 & & 130 & & 243 & 241 \\
\hline RsmA2 & 595 & 2.33 & & 135 & & 266 & & \\
\hline RsmA3 & 596 & 2.33 & & 128 & & 244 & & \\
\hline RsmE1 & 908 & 4 & 4 & 180 & 170 & 327 & 270 & 261 \\
\hline RsmE2 & 851 & 4.22 & & 150 & & 320 & & \\
\hline RsmE3 & 850 & 4.62 & & 181 & & 402 & & \\
\hline Rsml1 & 557 & 2.68 & 2.5 & 153 & 145 & 244 & 209 & 206 \\
\hline \multicolumn{9}{|l|}{ Rsml2 } \\
\hline Rsml3 & 596 & 2.53 & & 137 & & 238 & & \\
\hline
\end{tabular}

Shadowed in gray the discarded replicas.

${ }^{a}$ Confidence intervals of each data distribution, $\alpha=0.05$.

${ }^{b}$ After discarding redundancies where the analysis identifies more than one peak in a single RNA molecule.

\section{RESULTS AND DISCUSSION}

\section{Identification of RNAs Bound to Rsm Proteins}

Affinity purification of RNA-protein complexes followed by sequencing analysis (RAP-Seq), was carried out to identify genes that could potentially be regulated at the posttranscriptional level by RsmA, RsmE or RsmI in P. putida KT2440. The methodology was similar to that previously described for genome-wide mapping of targets for RsmN in Pseudomonas aeruginosa (Romero et al., 2018) and is summarized in Supplementary Figure S1. Each recombinant His-tagged Rsm protein (RsmA-His ${ }_{6}, \mathrm{RsmE}_{-} \mathrm{His}_{6}$ and RsmI-His ${ }_{6}$, previously described; Huertas-Rosales et al., 2016) was overexpressed in KT2440 as described in Materials and Methods. Proteins were purified by affinity chromatography and their associated target RNAs subsequently isolated. As control for transcription levels, total RNA was isolated from each culture in parallel. Total and Rsm-bound RNA were analyzed for purity, quantified and converted to cDNA for Illumina sequencing. One of the three biological replicates of RsmA and one of RsmI were below optimal quality and quantity and were not used in further analysis. Sequence reads from the cDNA libraries were mapped to the genomic sequence of $P$. putida KT2440 and analyzed to identify the regions corresponding to transcripts that were significantly enriched in the Rsm-bound RNA population with respect to the total RNA controls. Rsm-enriched RNAs that were not represented in the three technical replicates from each culture were not included in further analysis.

A first noticeable result was that the number of sequences corresponding to RsmE-bound transcripts overrepresented with respect to total RNA was much higher than those associated to RsmA or RsmI (Table 2). Data were grouped in intervals and histograms were built to analyze the distribution of foldenrichment (FE) values and $p$-value (PV) data-shown as $-10 \times \log _{10}(p$-value) for ease of representation-in each case (Figure 1). In all cases, the distribution was similar between biological replicates for each Rsm regulator. The distribution of FE values was similar for RsmA and RsmI, with slightly lower values in the former (Table 2). For RsmE, the distribution was different and the average values higher. These different values between Rsm proteins could reflect differences in expression of each construct. In fact, controls for each protein indicate that higher amount of RsmE than of the other two proteins is recovered after purification (Supplementary Figure S2).

The analysis of distributions and the confidence intervals calculated for each technical replicate were the basis to establish cut-off values for further analysis of Rsm targets (Table 3). Is should be noted that in this analysis we opted for rather strict parameters in order to take into account sequences strongly overrepresented in the Rsm-bound RNA population with respect to the total RNA controls, and also to minimize the number of potential false positives, at the expense of missing some RNA sequences that are actual targets of these proteins. Thus, the following cut-off values were established: PV $>130, \mathrm{FE} \geq 2.15$ for RsmA; PV $>170, \mathrm{FE} \geq 4$ for RsmE; PV $>145$, $\mathrm{FE} \geq 2.5$ for RsmI. Targets for which either value was below the cut-off in one of the replicates were discarded.

Using these parameters, 241, 261, and 206 RNA sequences were identified as targets for RsmA, RsmE and RsmI, respectively (Supplementary Table S1), corresponding to 437 unique transcripts, with 75 targets being shared by all three Rsm proteins and between 36 and 45 shared by two of them (Figure 2A). Interestingly, around $40 \%$ of the RsmE and RsmA targets are exclusive for each protein, while only $22 \%$ of the RsmI targets are unique for this paralog. It should be noted that the cDNA libraries generated in this study were not strandspecific and therefore, did not allow distinguishing the DNA strand to which the transcript corresponds. Consequently, in some cases where divergently transcribed genes are adjacent in the genome, it is not straightforward to discern which of them is the actual target, although the length of overlap between the enriched sequences and each gene, and the location of the summit (i.e. the position of maximal overlap of the reads corresponding to one region) can indicate the most likely target. Despite this limitation, the above results indicate that at least $12 \%$ of the transcripts in P. putida KT2440 are bound in vivo by Rsm proteins under the conditions tested in this study. The data provide a broad overview of the regulon and potential functions of these riboregulators. 
TABLE 3 | Annotation and functional classification of common targets for the three Rsm proteins in P. putida KT2440.

\begin{tabular}{|c|c|c|c|}
\hline Locus & Gene & Annotation & Notes \\
\hline \multicolumn{4}{|c|}{ Metabolism } \\
\hline PP_0053 & & sulfide:quinone oxidoreductase & Sulfur metabolism \\
\hline PP_0158 & gcdH & Glutaryl-CoA dehydrogenase & Operon (PP_0159: family III CoA-transferase) \\
\hline PP_0292 & hisA & $\begin{array}{l}\text { Phosphoribosylformimino-5-aminoimidazole carboxamide ribonucleotide } \\
\text { isomerase }\end{array}$ & Operon hisBHAF; histidine synthesis \\
\hline PP_0626 & $n d h$ & NADH dehydrogenase & \\
\hline PP_0711 & ycaC-I & Putative hydrolase & Isochorismatase family \\
\hline PP_1032 & guaA & Glutamine-hydrolyzing GMP synthase & Purine metabolism \\
\hline PP_1073 & $g / p D$ & Aerobic glycerol-3-phosphate dehydrogenase & \\
\hline PP_2080 & $g d h B$ & NAD-specific glutamate dehydrogenase & \\
\hline PP_2217 & & Enoyl-CoA hydratase & \\
\hline PP_2437 & & Acyl-CoA dehydrogenase & \\
\hline PP_2640 & & GNAT family acetyltransferase & \\
\hline PP_2681 & $\begin{array}{l}\text { pqqD- } \\
\|\end{array}$ & Pyrroloquinoline quinone biosynthesis chaperone & \\
\hline PP_4571 & cysk & Cysteine synthase $\mathrm{K}$ & Cysteine biosynthesis \\
\hline PP_5003 & phaA & poly (3-hydroxyalkanoate) polymerase & Synthesis of carbon/energy reserve polymers \\
\hline PP_5079 & aroK & Shikimate kinase & Biosynthesis of aromatic amino acids \\
\hline PP_5199 & ubiH & 2-Octaprenyl-6-methoxyphenyl hydroxylase & Ubiquinone biosynthesis \\
\hline \multicolumn{4}{|c|}{ Protein synthesis, degradation and modification } \\
\hline PP_1434 & era & GTPase Era & Maturation of $16 \mathrm{~S}$ rRNA and assembly of the $30 \mathrm{~S}$ ribosomal subunit \\
\hline PP_1443 & lon-I & DNA-binding ATP-dependent protease & $\begin{array}{l}\text { Might indirectly regulate the levels and activity of sRNAs through } \\
\text { stability of hfq }\end{array}$ \\
\hline PP_3620 & yсаO & Ribosomal protein S12 methylthiotransferase accessory factor & Post-translational peptide modification \\
\hline PP_4559 & def-II & Peptide deformylase & Processing of nascent peptides \\
\hline PP_5364 & clsA & Cardiolipin synthase & \\
\hline
\end{tabular}

Transport and secretion

\begin{tabular}{|c|c|c|c|}
\hline & RND family multidrug transporter & \multirow[t]{3}{*}{ Antimicrobial resistance } \\
\hline \multirow{2}{*}{\multicolumn{2}{|c|}{$\begin{array}{l}\text { PP_0907 } \\
\text { PP_1015 gtsA } \\
\text { PP_2195 }\end{array}$}} & Mannose/glucose $\mathrm{ABC}$ transporter substrate-binding protein & \\
\hline & & Periplasmic putrescine-binding protein & \\
\hline PP_3089 & hсp1 & Type VI secretion system effector protein & Part of the K1-T6SS \\
\hline PP_3099 & tssC1 & Type VI secretion system & Part of the K1-T6SS \\
\hline PP_3108 & tke2 & Type VI secretion system effector protein & Part of the K1-T6SS \\
\hline PP_4542 & & ABC transporter ATP-binding protein/permease & \\
\hline
\end{tabular}

Stress response

PP_1210 dps DNA-binding stress protein

PP_3156 Universal stress protein family

PP_3234 HSP20 family heat shock protein

PP_3312 HSP20 family heat shock protein

PP_4541 ppiA Peptidyl-prolyl cis-trans isomerase A

Putative chaperone

Putative chaperone

Protein folding; stress response and biofilm in different bacteria

Signal transduction and regulation

\begin{tabular}{|c|c|c|c|}
\hline PP_0173 & & Transcriptional factor-like protein & Winged helix DNA binding domain \\
\hline PP_0546 & & Sigma-54 dependent transcriptional regulator & Putative acetoin metabolism regulator \\
\hline PP_0563 & & Two-component system respose regulator - GGDEF domain & c-di-GMP turnover \\
\hline PP_1492 & $w s p E$ & $\begin{array}{l}\text { Two-component system sensor histidine kinase/response regulator (CheA } \\
\text { WspE) }\end{array}$ & Part of the wsp cluster (biofilm formation) \\
\hline PP_3761 & $C f C A$ & Two-component system sensor histidine kinase/response regulator & CfcR phosphorylation and activation \\
\hline PP_3765 & $\operatorname{tur} B$ & H-NS family protein (MvaT homolog) & Repressor of gene expression \\
\hline PP_3832 & rsme & Post-transcriptional regulatory protein RsmE & \\
\hline PP_4099 & uvrY & Two-componenent system response regulator & Operon with uvrC (nucleotide excision repair) \\
\hline \multicolumn{4}{|c|}{ Non-coding RNAs } \\
\hline PP_mr05 & $r s m Y$ & Non-coding RNA & \\
\hline PP_mr44 & & Non-coding RNA & \\
\hline PP_mr52 & & Non-coding RNA & \\
\hline
\end{tabular}


TABLE 3 | (Continued) Annotation and functional classification of common targets for the three Rsm proteins in P. putida KT2440.

\begin{tabular}{|c|c|c|c|}
\hline Locus & Gene & Annotation & Notes \\
\hline \multicolumn{4}{|c|}{ DNA recombination and transposition } \\
\hline PP_1813 & & comEA-like protein & DNA binding and recombination domain \\
\hline PP_1865 & & Transposase ISPpu8 + intergenic region & \\
\hline PP_2114 & & Transposase ISPpu8 + intergenic region & \\
\hline intergenic & & Putative ISPpu8 insertion site & Long palindromic region downstream PP_3547 \\
\hline PP_4318 & & Transposase ISPpu8 + intergenic region & \\
\hline \multicolumn{4}{|c|}{ Cell envelope and appendages (LPS, EPS, pili) } \\
\hline PP_0063 & $(\mid p x L)$ & Lipid a biosynthesis lauroyl acyltransferase & LPS synthesis \\
\hline PP_2926 & $u d g$ & UDP-glucose 6-dehydrogenase & may be involved in LPS synthesis \\
\hline PP_3139 & & Group 1 family glycosyl transferase & Part of the pea operon - EPS synthesis \\
\hline PP_4795 & & Lipoprotein & LptE family - LPS assembly \\
\hline PP_4920 & & Lipoprotein & PdaC superfamily (polysaccharide deacetylase) \\
\hline PP_5083 & pilM & Type IV pili biogenesis protein PilM & Operon 5083-5079 (type IV pili + aroK) \\
\hline \multicolumn{4}{|c|}{ Hypothetical/unknown function } \\
\hline PP_5720 & & Pseudogene & \\
\hline PP_0085 & & Hypothetical protein & YajD/ElaB family (stress response?) \\
\hline PP_1499 & & Hypothetical protein & \\
\hline PP_1887 & & Hypothetical protein - YD repeat domain & Repeats may bind carbohydrates \\
\hline PP_2219 & & Hypothetical protein & \\
\hline PP_2345 & & Hypothetical protein & \\
\hline PP_2396 & & Hypothetical protein & Periplasmic protein \\
\hline PP_3007 & & Hypothetical protein & \\
\hline PP_3010 & & Hypothetical protein & Putative lipoprotein \\
\hline PP_3130 & & Hypothetical protein & Glycoside hydrolase family (EPS turnover?) \\
\hline PP_3580 & & Hypothetical protein & \\
\hline PP_3662 & & Hypothetical protein & Nucleotide 5'-monophosphate nucleosidase YgdH-like superfamily \\
\hline PP_3901 & & Hypothetical protein & Predicted phage protein \\
\hline PP_3909 & & Hypothetical protein & \\
\hline PP_3963 & & Hypothetical protein & Stress-induced protein (KGG repeat) domain \\
\hline PP_4793 & & Hypothetical protein & \\
\hline PP_5099 & & Hypothetical protein & \\
\hline PP_5209 & & Hypothetical protein & FliL-like protein \\
\hline PP_5232 & & Hypothetical protein & \\
\hline PP_5395 & & Hypothetical protein & Branched-chain polyamine synthase domain \\
\hline
\end{tabular}

Analysis of RsmA, RsmE and Rsml Targets The 75 targets common to the three Rsm proteins are compiled in Table 3, broadly classified according to their functions. As reflected in Figure 2B, about half of the common targets correspond to two categories: metabolism-related and hypothetical proteins. The fact that functions related to central metabolism and carbon storage are among these common targets is not unexpected, since carbon metabolism was at the origins of the identification of the CsrA/Rsm family of proteins (Sabnis et al., 1995). Other expected elements include RNAs corresponding to Rsm proteins themselves: $r s m E$ is a target for the three proteins, and $r s m A$ is recognized by RsmE, confirming previous expression data that indicated the existence of self- and cross-regulation of these proteins (Huertas-Rosales et al., 2016). Also expected was the small non-coding RNA rsmY, known to bind and titrate Rsm proteins (Sonnleitner and Haas, 2011; Janssen et al., 2018). Binding of $r s m Y$ to the three Rsm proteins could be confirmed in vitro by EMSA analysis (Figure 3), serving as positive control that the high throughput methodology used was successful, although the affinity appears to be different in each case, being RsmI the protein that required higher concentrations for binding to be detected. A second small RNA previously identified in P. putida, rsmZ (Huertas-Rosales et al., 2016), involved in titration of Rsm proteins in other bacteria (Janssen et al., 2018), is among the targets common to RsmA and RsmE (Table 4, Supplementary Table S1). Other non-coding RNAs could also be identified as bound to one, two or the three Rsm proteins (Table 2). This might suggest a possible ancillary role in titration of Rsm proteins, which led us to analyze them in some detail. Secondary structure predictions indicate that GGA motifs in short stem-loop structure, typical targets for CsrA/RsmA recognition (Dubey et al., 2005; Duss et al., 2014), are present in at least some of these RNA molecules, namely PP_mr15, PP_mr49 and PP_mr55 (Supplementary Figure S3). However, while $r s m Y$ and $r s m Z$ show several of these motifs, only one per molecule was present in the other three. Also, conserved GacA binding sites, involved in transcriptional regulation of Rsm-titrating RNAs in other Pseudomonas species (Brencic et al., 2009) could be identified in the regions upstream 

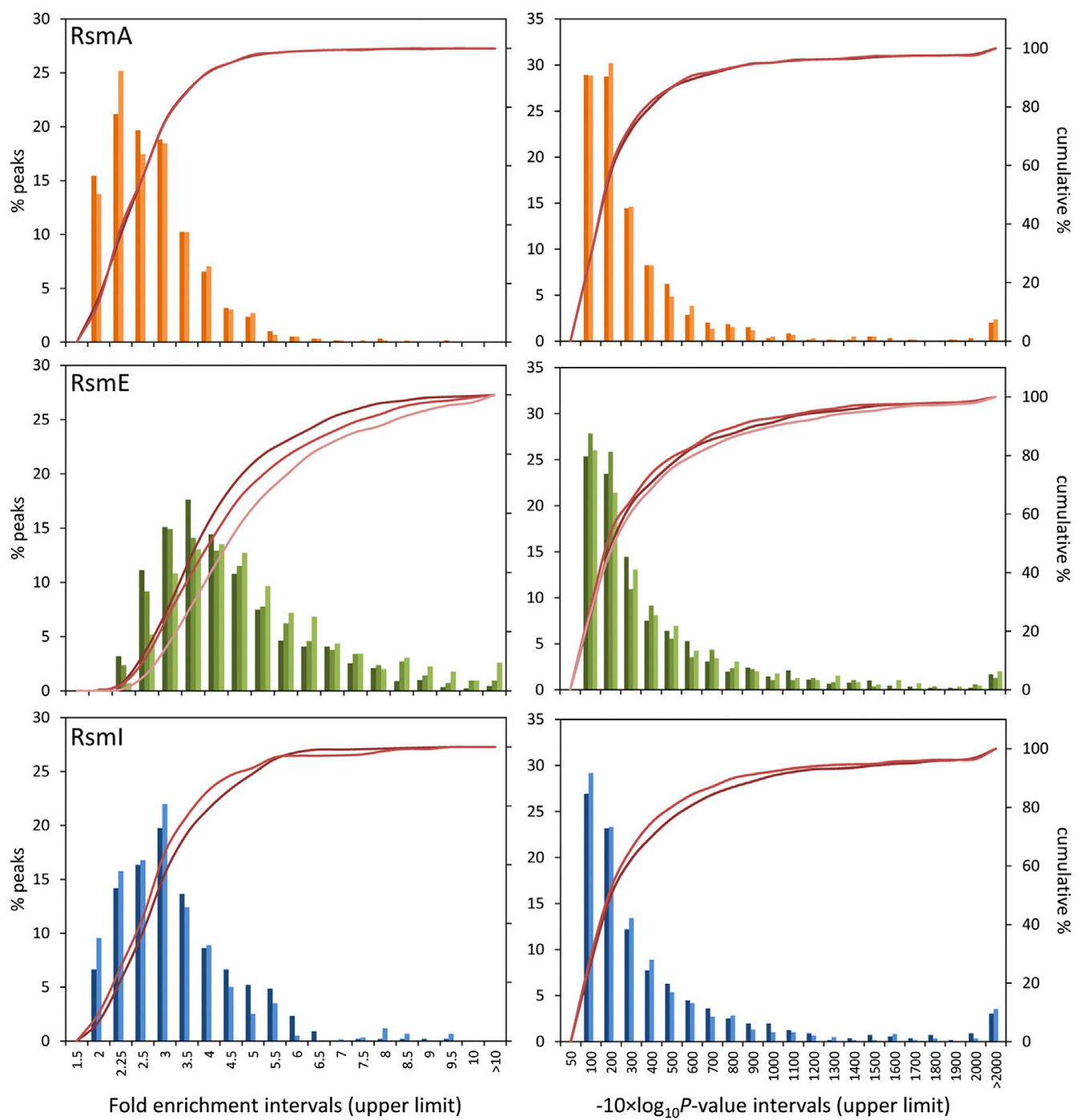

FIGURE 1 | Distribution of fold enrichment (left) and -10 $\times \log _{10}(p$-value) scores (right) data of overrepresented RNA sequences associated to each Rsm protein (orange, RsmA; green, RsmE; blue, Rsml) with respect to total RNA. Data were grouped in the value intervals indicated in the $X$-axis, where the number corresponds to the upper limit of each interval. The histograms (primary $Y$-axis) show the frequency of targets in each interval. The crimson lines (secondary $Y$-axis) correspond to the cumulative percent values. The different color intensities in the histograms and lines correspond to the different biological replicates for each protein.

A Target RNAs

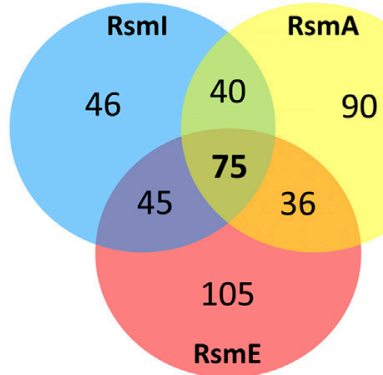

B Classification of common targets

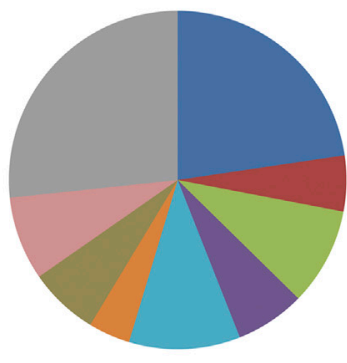

Metabolism

- Protein fate

- Transport and secretion

atress

- Signal transduction \& regulation

- Non coding RNAs

Recombination \& transposition

- Cell envelope $\&$ appendages

nypothetical

FIGURE 2 | (A) Venn diagram summarizing the number of targets identified for the three Rsm proteins in P. putida KT2440, according to the selection parameters detailed in the text. (B) Graphical representation of the different functional categories encompassing the 75 common targets. 
TABLE 4 | Non-coding RNAs identified as targets for each Rsm protein.

\begin{tabular}{lcccc} 
& & \multicolumn{3}{c}{ Fold-enrichment $^{\mathbf{a}}$} \\
\cline { 4 - 5 } Locus $^{\mathbf{b}}$ & Length (bp) & RsmA & RsmE & Rsml \\
\hline PP_mr05 (rsmY) & 127 & 8.36 & 16.46 & 6.88 \\
PP_mr15 & 209 & 3.83 & 5.37 & $(3.49)$ \\
PP_mr22 (rsmZ) & 134 & 4.58 & 11.58 & $(5.11)$ \\
PP_mr44 & 385 & 2.87 & 6.49 & 3.22 \\
PP_mr49 & 97 & 3 & - & $(3)$ \\
PP_mr52 & 149 & 2.36 & 6.96 & 4.72 \\
PP_mr53 & 395 & 3.93 & $(3.76)$ & 3.53 \\
PP_mr55 & 82 & - & 5.20 & - \\
PP_mr57 & 254 & 8.17 & - & - \\
PP_mr59 & 97 & 2.42 & $(2.96)$ & $(2.1)$
\end{tabular}

${ }^{a}$ Values in parentheses indicate targets below the $\mathrm{p}$-value and/or fold-enrichment cutoffs Minus sign indicates the target is not present in one or more of the enriched RNA replicas.

${ }^{b}$ Annotated according to 54

rsm $Y$ and $r s m Z$, being only partially conserved in PP_mr55 (Supplementary Figure S4), and absent in the remaining RNAs (not shown). All these data suggest that $\operatorname{rsm} Y$ and $r s m Z$ are the main, if not the only, true antagonists of Rsm proteins in $P$. putida. The remaining non-coding RNAs that are targets of these proteins may regulate further downstream elements in the Gac/Rsm cascade.

Additionally, several intergenic sequences were found among the targets for the three proteins. These correspond to regions adjacent to the different copies of the ISPpu8 transposase in the genome of $P$. putida KT2440 or are potential insertion sites (or remnants of previous insertions) of this transposase, based on their sequence identity with ISPpu8 flanking regions. Whether Rsm proteins influence the activity of this mobile genetic element in KT2440 is an interesting issue that deserves further study.

As mentioned above, a significant number of targets seem to be exclusive for one of the three proteins. A few of these correspond to enriched peaks that were below the established cut-off parameters in some samples, and therefore could represent common targets showing different affinities for each protein, with a strong preference for one of them. Such is the case, for example, of PP_0013 ( $g y r B)$, which is among the above-cut-off targets for RsmA but slightly below the FE and/or $p$-value cut-off for the other two proteins. Other targets are only enriched in association with one of the Rsm proteins and are not present in the RNA population associated to either of the other two, indicating they are truly specific for that Rsm homolog, e.g. PP_1656 (relA) for RsmA, PP_0168 (lapA) for RsmE, or PP_1803 ( $w p b V$ ) for RsmI. Identifying the molecular basis for such specificity will require detailed bioinformatics analysis combined with in vitro and in vivo assays.

Supplementary Figure S5 provides data corresponding to $\beta$-galactosidase activity of several translational fusions of identified targets to lacZ in the wild type KT2440 and a triple rsmArsmErsmI deletion mutant, $\triangle$ IEA (HuertasRosales et al., 2016). In most cases, expression was enhanced in the mutant, indicating that the observed
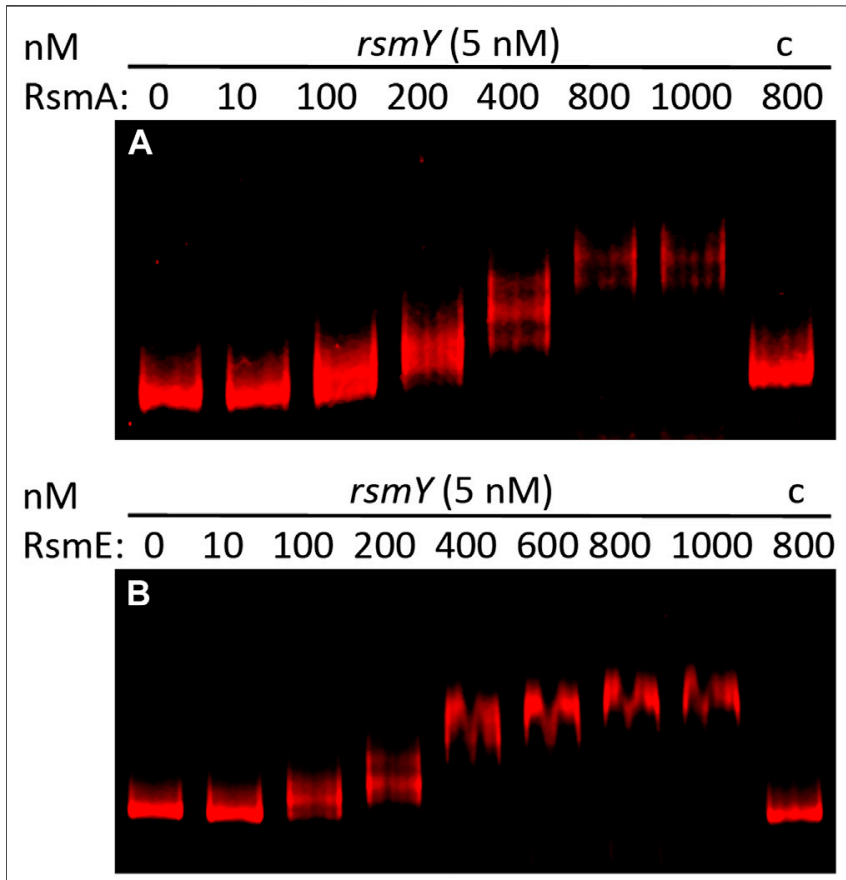

$\mathrm{nM}$ $r \operatorname{sm} Y(5 \mathrm{nM})$ C

Rsml:

$0 \quad 10 \quad 100 \quad 200400 \quad 800 \quad 1000 \quad 800$

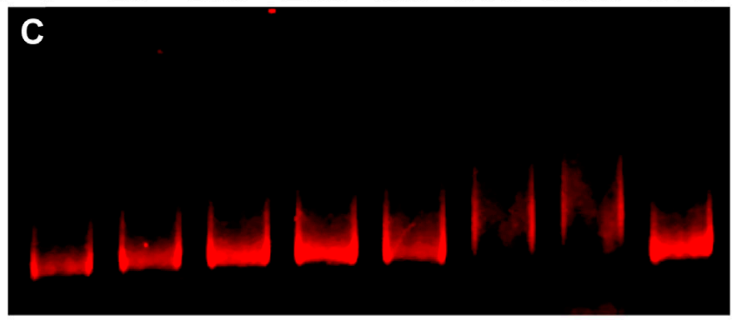

$\mathrm{nM}$ $\operatorname{rpos}(10 \mathrm{nM})$ C RsmA: $0 \quad 100 \quad 300 \quad 500 \quad 650 \quad 800 \quad 1000 \quad 650$

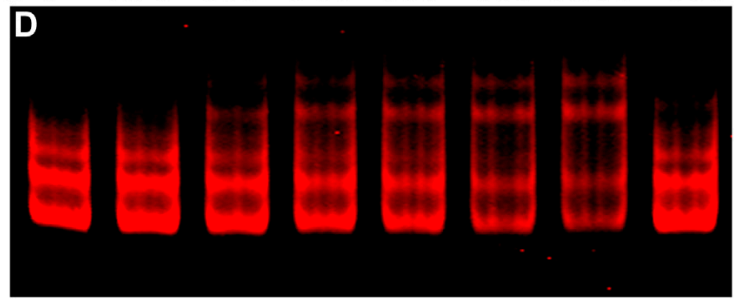

FIGURE 3 | Binding of RsmA-His 6 (A), RsmE-His ${ }_{6}$ (B) and Rsml-His 6 (C) to full-length rsmY RNA transcribed in vitro, and of RsmA-His ${ }_{6}$ to a synthetic RNA fragment comprising the untranslated upstream region of rpoS (D). EMSAs were carried out using fluorescently labeled RNA (5 or $10 \mathrm{nM}$ ) and incubated in the absence or presence of increasing concentrations of purified Rsm proteins, as indicate above each lane, or in the presence of $100-$ fold excess of unlabelled RNA competitor and the indicated concentration of protein (C).

binding to their RNA targets leads to translation repression by these proteins; these results are consistent with previous observations on their influence upon 
biofilm-related elements (see below). However, the inverse was true for two of the tested fusions, those corresponding to PP_1088 (argG, involved in arginine synthesis; RamosGonzález et al., 2016) and PP_4482 (part of the gene cluster encoding the main arginine transporter and its regulator; Barrientos-Moreno et al., 2020). In these cases, expression was approximately halved in the mutant with respect to the wild type.

\section{C-Di-GMP Signaling and Biofilm-Related Targets}

As indicated in the Introduction, the three Rsm proteins have been shown to bind a specific site in the mRNA corresponding to the response regulator with diguanylate cyclase activity $\mathrm{CfcR}$, and a triple rsm mutant in KT2440 shows increased levels of c-di-GMP and altered biofilm dynamics (HuertasRosales et al., 2016; Huertas-Rosales et al., 2017). Intriguingly, $c f c R$ mRNA was not among the common targets listed in Table 3, being only found as target for RsmE and RsmI. The $c f c R$ transcript is actually among the RsmA-bound RNA sequences overrepresented with respect to the control RNA, but the FE values (1.82 and 1.88 in each replicate, respectively) are below the established cut-off. This could indicate that binding of RsmA to the mRNA of $c f c R$ in vivo is hampered by competition with the other two Rsm proteins, a possibility that has been previously suggested, based on in vivo expression data of $c f c R$ compared to the high affinity observed for the $\mathrm{RsmA} / c f c R$ mRNA interaction in vitro (HuertasRosales et al., 2017).

Besides $c f c R$, transcripts from four other genes encoding proteins predicted to participate in c-di-GMP turnover and signaling were identified in this analysis, one of them (encoded by locus PP_0563) as target of the three proteins, and the rest (PP_0386, PP_0914, PP_2505), as targets of RsmE. Of these, the proteins encoded by PP_0563 and PP_2505 present GGDEF domains, characteristic of diguanylate cyclases. The first corresponds to GcbA, a diguanylate cyclase conserved in Pseudomonas, which has been reported to influence initial attachment and swimming motility (Petrova et al., 2014; Xiao et al., 2016). PP_0914 corresponds to the EAL domaincontaining phosphodiesterase BifA, described to regulate biofilm development in P. putida (Jiménez-Fernández et al., 2015), and PP_0386 encodes a protein containing both GGDEF and EAL domains. Other relevant biofilm-related transcripts bound by RsmE included: $\operatorname{lapA}$, encoding the main adhesin of $P$. putida, essential for initial attachment and biofilm formation (Hinsa et al., 2003; Martínez-Gil et al., 2010); the first gene in the cellulose synthesis operon; and genes in the operon encoding the species-specific EPS Pea

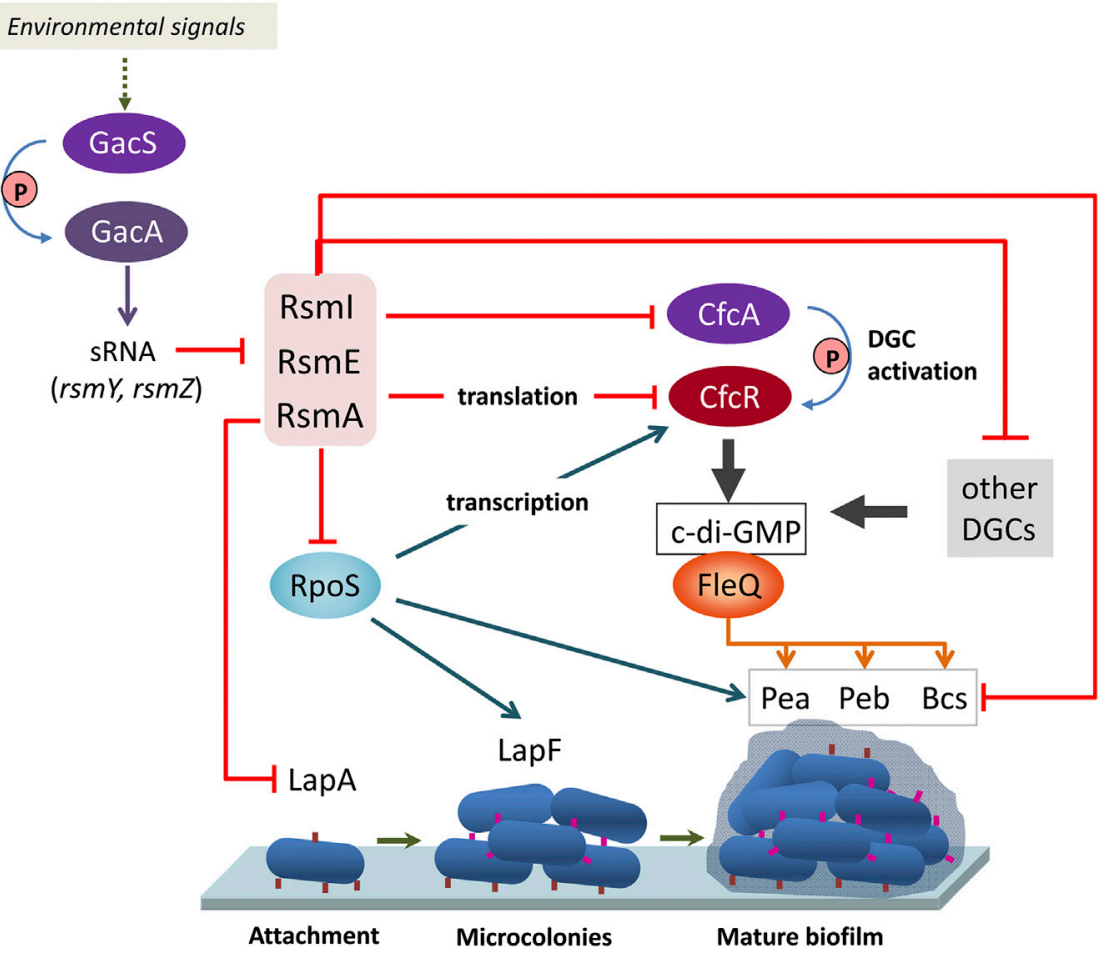

FIGURE 4 | Schematic view of the connection between the Gac/Rsm signaling cascade with biofilm formation through c-di-GMP turnover, adhesins and exopolysaccharides. The Rsm proteins exert a complex regulation on the response regulator with DGC activity CfcR, at the transcriptional (via RpoS), translational (via direct binding), and post-translational (via the histidine kinase CfcA, required for phosphorylation of CfcR) levels. Direct influence of Rsm proteins on structural elements of the biofilm matrix, and indirect influence via RpoS and the c-di-GMP associated regulator FleQ are also depicted. Blue arrows indicate positive regulation and red lines negative regulation. 
(Nilsson et al., 2011), which is also a target for RsmA. Neither lapF, encoding the second relevant adhesin present in KT2440 (Martínez-Gil et al., 2010), nor the other two EPS operons described in this strain (Nilsson et al., 2011) were identified in this analysis.

Since altered expression of translational fusions corresponding to some of the genes indicated aboved has been previously observed in a triple rsmAEI mutant (Huertas-Rosales et al., 2016), it is likely that the observed expression changes are due to an indirect effect of Rsm proteins through other regulators. One such regulator is the stationary phase sigma factor RpoS, which controls expression of lapF (Martínez-Gil et al., 2010). RpoS was found to be negatively regulated by RsmA In $P$. protegens CHA0 (Heeb et al., 2005), and the mRNA corresponding to rpoS (PP_1623) is among the targets for RsmA in KT2440 (Supplementary Table S1). Moreover, binding of RsmA to an in vitro transcribed RNA fragment containing the ribosome binding site and start codon of rpoS was confirmed via EMSA (Figure 3). Given that expression of $c f c R$ is also regulated by RpoS (Matilla et al., 2011), these results support the previously proposed model whereby Rsm proteins exert a dual control, direct and indirect, on $c f c R$ (Huertas-Rosales et al., 2017). Remarkably, the gene $c f c A$, encoding a sensor histidine kinase essential for activation of CfcR (Ramos-González et al., 2016), is among the targets for the three proteins, indicating that c-di-GMP signaling through $\mathrm{CfCR}$ is tightly regulated by the Gac/Rsm network. A schematic view of this signaling cascade connecting external stimuli with biofilm formation through Rsm elements is depicted in Figure 4.

\section{Influence of Rsm Proteins on Nutrient Utilization and Rhizosphere Fitness of P. putida KT2440}

Among the shared targets for the three riboregulators, about a third of the transcripts with known or predicted functions correspond to genes with metabolism-related roles in KT2440 (Figure 2B and Table 4). This was expected since previous findings have established direct and indirect connections between the CsrA/Rsm system and metabolism as well as carbon storage functions (Sabnis et al., 1995; Yang et al., 1996; Pannuri et al., 2016; Romero et al., 2018). Furthermore, a significant number of targets identified for one or more of the Rsm proteins included transcripts from genes related to transport of nutrients (Figure 2B and Table 3). All this prompted us to carry out a preliminary high throughput study comparing the growth of KT2440 wild type strain and a triple $r s m A E I$ mutant derivative ( $\triangle I E A$; Huertas-Rosales et al., 2016) in BIOLOG plates using 192 and 96 compounds as sole carbon or nitrogen source, respectively. A sample of some of the obtained data is shown in Supplementary Figure S5. Growth differences between the two strains were observed for several compounds, particularly certain amino acids and their derivatives. Further detailed evaluation of growth in some of these compounds confirmed the existence of differences between KT2440 and the triple rsm mutant. In particular, a prolonged
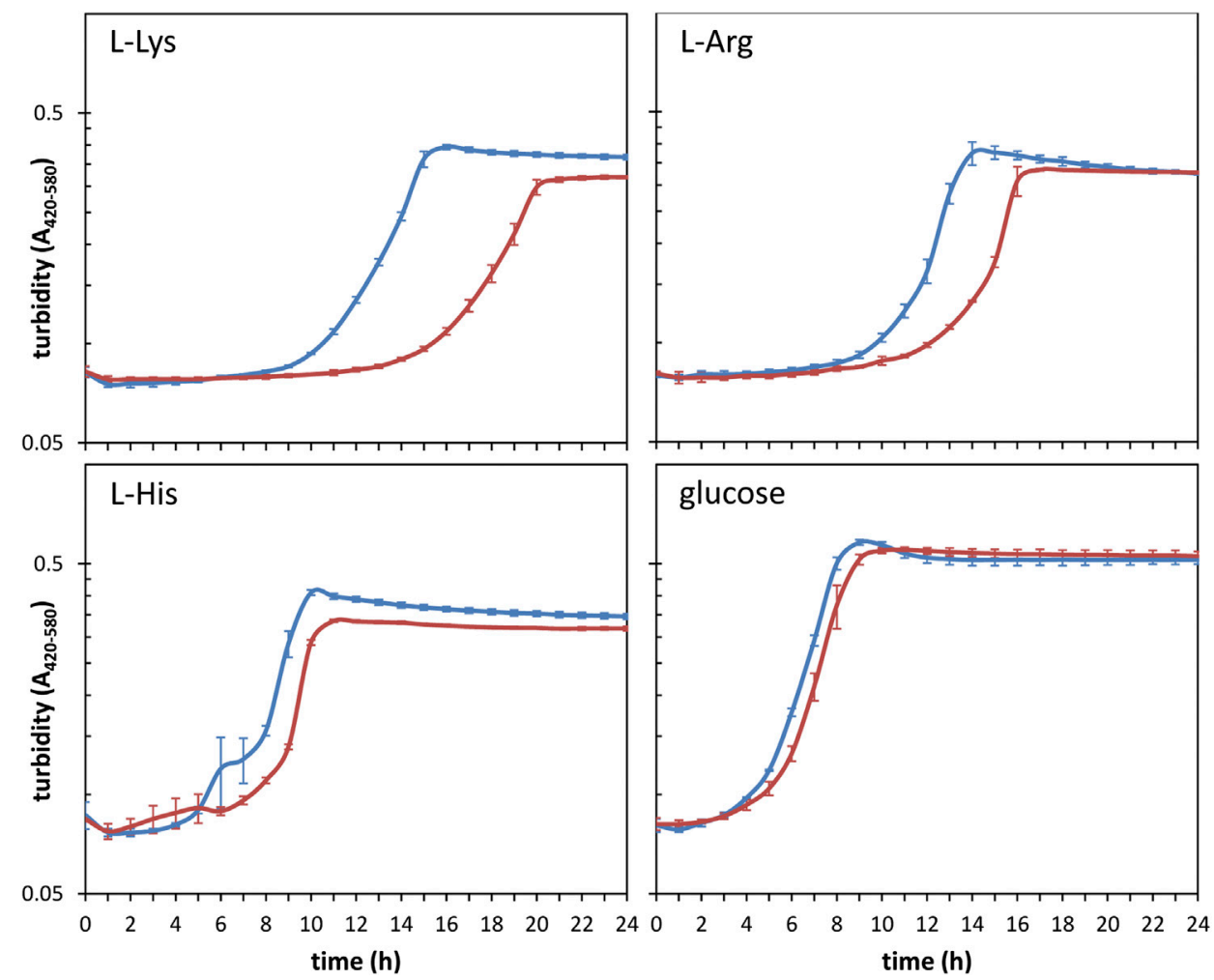

FIGURE 5 | Growth of KT2440 (blue) and the triple rsm mutant (red) in M9 minimal medium with 5 mM L-lysine, L-arginine, L-histidine or glucose as carbon source. Cultures were grown in $96-$ well plates at $30^{\circ} \mathrm{C}$ and $\mathrm{OD}_{420-580}$ was read at 1 -h intervals in an automated BioScreen equipped with a wide band filter (420-580 nm) to minimize potential alterations due to changes in medium color. Data are averages and standard deviations of experiments done in duplicate, with three technical replicas each. 
lag phase was observed in the mutant with L-lysine as carbon source, and to a lesser extent with L-arginine, although the final turbidity reached by both strains with this last amino acid was similar (Figure 5). In contrast, growth differences were less evident with the other basic amino acid L-histidine (Figure 5).

These results evidenced that the Rsm system may play a regulatory role in metabolism and/or uptake of nutrients, particularly of basic amino acids, in KT2440. Hence, potential Rsm-enriched targets explaining these divergences were explored. A survey of the identified RNA molecules related to these processes indicated that those corresponding to $\operatorname{arcD}$ (PP_1002; arginineornithine antiporter) and hisP (PP_4483; ATP-binding subunit of a histidine/lysine/arginine/ornithine transporter) are targets for RsmE; artJ (PP_0282; L-arginine ABC transporter substrate-binding subunit) and amaD (PP_3596; D-lysine oxidase) are targets for RsmA, and $a m a B$ (PP_5258; L-piperidine-6-carboxylate dehydrogenase) is a target for both RsmE and RsmI (Supplementary Table S1). Based on data from the Kyoto Encyclopedia of Genes and Genomes (www. genome.jp/kegg/), AmaB is involved in catabolic pathways for L-lysine and L-arginine in P. putida, participating in the conversion of aminobutanal, N4-acetyl-aminobutanal, and 4-trimethylammoniobutanal into their corresponding butanoate derivatives.

Besides glucose metabolism, a connection has been established in E. coli between CsrA and the stringent response (Edwards et al., 2011), a regulatory network triggered by amino acid limitation and controlled by the RelA and SpoT proteins. It should be noted that besides the targets indicated above in relation with arginine and lysine utilization, the relA (PP_1656) mRNA is also a target for RsmA (Supplementary Table S1).

Previous reports have established that his $P$ and genes involved in lysine catabolism are preferentially expressed in KT2440 in the rhizosphere of corn plants (Espinosa-Urgel and Ramos, 2001; Matilla et al., 2007). In addition, a connection beween arginine transport and c-di-GMP signaling in this strain has been recently reported (Barrientos-Moreno et al., 2020). These facts, and the influence of Rsm proteins on biofilm formation and surface motility, along with the identification of c-di-GMP turnover elements and other biofilm-related genes as targets of these proteins, made us analyze if mutants in $r s m$ genes showed altered fitness in the rhizosphere. Competitive root colonization assays were done in corn (Zea mays L.) plants with the wild type and single $(\Delta \mathrm{I}$, $\Delta \mathrm{E}, \Delta \mathrm{A})$, double $(\Delta \mathrm{IE}, \Delta \mathrm{IA}, \Delta \mathrm{EA})$ and the triple $(\Delta \mathrm{IEA}) r s m$ mutants (Huertas-Rosales et al., 2016). For that purpose, germinated corn seeds were inoculated with miniTn7Km-tagged KT2440 and each mutant tagged with miniTn7Sm, in a 1:1 proportion. Plants were sown in sterile sand and the population of each strain was evaluated in the whole root and in the root tip after 7 days. Results are shown in Figure 6. The mutation in $\operatorname{rsm} A$ caused a slight reduction in competitive colonization of the whole root and a much larger effect when root tip colonization was evaluated. This phenotype was not observed in the other single mutants, nor in the $\Delta \mathrm{IE}$ double mutant. However, while the results with the $\Delta \mathrm{IA}$ double mutant were similar to those obtained with the $\Delta \mathrm{A}$ single mutant, a cumulative effect could be observed in the $\Delta \mathrm{EA}$ strain, which showed a significant decrease in colonization of both the whole root and the root tip. This phenotype was very similar to that observed in the triple mutant. In this set of experiments the Sm resistance marker seemed to

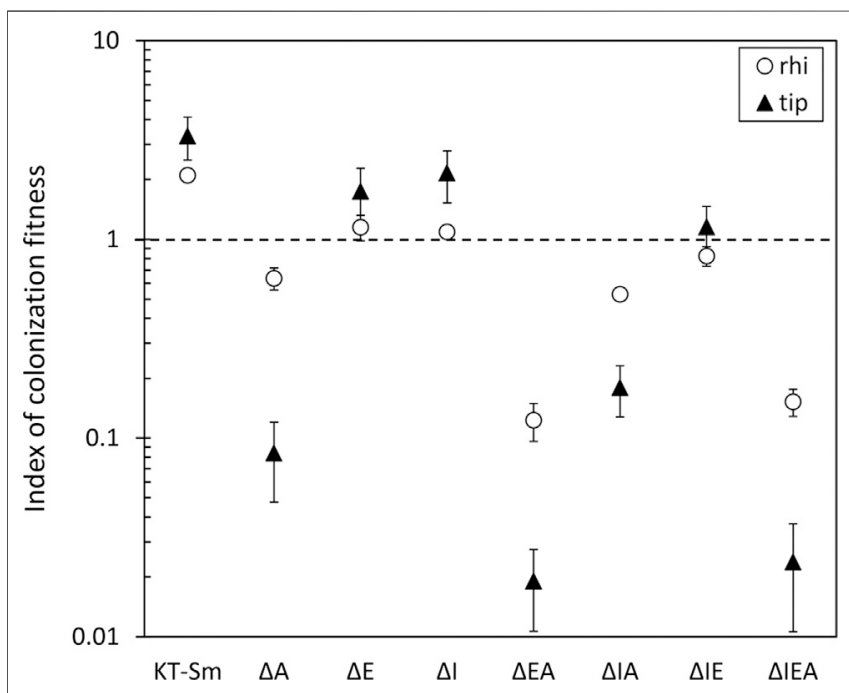

FIGURE 6 | Colonization capacity of mutants in rsm genes in competition with the wild type in the rhizosphere (circles) and the root tip (triangles) of corn plants. KT2440 tagged with miniTn7-Km was co-inoculated in a 1:1 proportion with each of the mutants, which were tagged with miniTn7-Sm. To check the potential effect of the antibiotic resistance markers, a competitive colonization assay co-inoculating KT2440 miniTn7-Km and KT2440 miniTn7-Sm (KT-Sm) was also included as control. The index of colonization fitness was measured as 1/[(percentage of recovered wild type vs. each mutant per plant 7 days post-inoculation)/(percentage wt vs. mutant in the initial inocula)]. A value of 1 (broken line) indicates equal colonization capacity. Data are the averages and standard errors for six plants.

confer a slight advantage over the $\mathrm{Km}$ resistance marker, according to the results obtained with the wild type derivatives tagged with each mini-Tn7 (Figure 6). This could suggest that the actual influence of the rsm mutations might be larger than observed here.

The loss of fitness in the rhizosphere of the $\triangle \mathrm{EA}$ and $\triangle \mathrm{IEA}$ mutants may result from the overall influence of Rsm proteins on different metabolic processes, including amino acid transport, while the reduction in root tip colonzation could correlate with the previously observed decrease in swimming motility in the $\triangle \mathrm{EA}$ and $\triangle$ IEA strains and the lack of swarming motility of all the rsm mutants, with the exception of $\Delta \mathrm{I}$, which still retained some surface motility (Huertas-Rosales et al., 2016). It will also be of interest to explore whether the type VI secretion system K1, some of whose genes were identified in our study (Table 3), may contribute to the fitness of KT2440 in the rhizosphere. It has been reported that this system can provide a competitive advantage to this strain in the presence of phytopathogenic bacteria (Bernal et al., 2017).

\section{CONCLUDING REMARKS}

This work represents the first effort to define the global regulatory network commanded by Rsm proteins in P. putida. Besides exposing its complexity and the vast influence that post-transcriptional regulation is bound to have in this bacterium, ranging from amino acid metabolism to potential transposon-mediated DNA rearrangements, the information obtained leads to a relevant question to be analyzed in detail, i.e. the characteristics by which 
an RNA molecule constitutes a shared target for the three Rsm proteins or is selectively bound by only one or two of them.

\section{DATA AVAILABILITY STATEMENT}

The datasets presented in this study can be found in online repositories. The names of the repository/repositories and accession number(s) can be found in the article/Supplementary Material.

\section{AUTHOR CONTRIBUTIONS}

OH-R, MR, K-WH, LB-M, MAM-H, MT performed the experimental work; OH-R, MR, MC, SH, MIR-G, ME-U designed the work; OH-R, MR, K-GC, MC, SH, MIR-G, ME-U analyzed data; MC, SH, K-GC, MIR-G, MEU obtained funding; OH-R, ME-U wrote the paper; All authors have revised the manuscript.

\section{REFERENCES}

Ausubel, F. M., Brent, R., Kingston, R. E., Moore, D. D., Seidman, J. G., Smith, J. A., et al. (1987). Current protocols in molecular biology. New York, NY: Wiley.

Baker, C. S., Eöry, L. A., Yakhnin, H., Mercante, J., Romeo, T., and Babitzke, P. (2007). CsrA inhibits translation initiation of Escherichia coli hfq by binding to a single site overlapping the Shine-Dalgarno sequence. J. Bacteriol. 189, 5472-5481. doi:10.1128/JB.00529-07

Barrientos-Moreno, L., Molina-Henares, M. A., Ramos-González, M. I., and Espinosa-Urgel, M. (2020). Arginine as an environmental and metabolic cue for cyclic diguanylate signalling and biofilm formation in Pseudomonas putida. Sci. Rep. 10 (1), 13623. doi:10.1038/s41598-020-70675-x

Bernal, P., Allsopp, L. P., Filloux, A., and Llamas, M. A. (2017). The Pseudomonas putida T6SS is a plant warden against phytopathogens. ISME J. 11, 972-987. doi:10.1038/ismej.2016.169

Brencic, A., and Lory, S. (2009). Determination of the regulon and identification of novel mRNA targets of Pseudomonas aeruginosa RsmA. Mol. Microbiol. 72, 612-632. doi:10.1111/j.1365-2958.2009.06670.x

Brencic, A., McFarland, K. A., McManus, H. R., Castang, S., Mogno, I., Dove, S. L., et al. (2009). The GacS/GacA signal transduction system of Pseudomonas aeruginosa acts exclusively through its control over the transcription of the RsmY and RsmZ regulatory small RNAs. Mol. Microbiol. 73, 434-445. doi:10. 1111/j.1365-2958.2009.06782.x

Choi, K. H., Kumar, A., and Schweizer, H. P. (2006). A 10-min method for preparation of highly electrocompetent Pseudomonas aeruginosa cells: application for DNA fragment transfer between chromosomes and plasmid transformation. J. Microbiol. Methods 64, 391-397. doi:10.1016/j.mimet.2005.06.001

Coggan, K. A., and Wolfgang, M. C. (2012). Global regulatory pathways and crosstalk control Pseudomonas aeruginosa environmental lifestyle and virulence phenotype. Curr. Issues Mol. Biol. 14, 47-70.

Dubey, A. K., Baker, C. S., Romeo, T., and Babitzke, P. (2005). RNA sequence and secondary structure participate in high-affinity CsrA-RNA interaction. RNA 11, 1579-1587. doi:10.1261/rna.2990205

Duss, O., Michel, E., Diarra dit Konté, N., Schubert, M., and Allain, F. H. (2014). Molecular basis for the wide range of affinity found in Csr/Rsm protein-RNA recognition. Nucleic Acids Res. 42, 5332-5346. doi:10.1093/nar/gku141

Edwards, A. N., Patterson-Fortin, L. M., Vakulskas, C. A., Mercante, J. W., Potrykus, K., Vinella, D., et al. (2011). Circuitry linking the Csr and stringent response global regulatory systems. Mol. Microbiol. 80, 1561-1580. doi:10.1111/j.1365-2958.2011.07663.x

Espinosa-Urgel, M., and Ramos, J. L. (2001). Expression of a Pseudomonas putida aminotransferase involved in lysine catabolism is induced in the rhizosphere. Appl. Environ. Microbiol. 67, 5219-5224. doi:10.1128/AEM.67.11.5219-5224.2001

\section{ACKNOWLEDGMENTS}

This work was supported by grants BFU2013-43469-P, BFU2016-80122-P and PID2019-109372GB-I00 from the Plan Estatal de I+D+I (Agencia Estatal de Investigación, Spanish Ministry of Science and Innovation and FEDER funds). Funding from the Biotechnology and Biological Sciences Research Council, United Kingdom (BB/R012415/1), and the University of Malaya (FRGS grant FP022-2018A and HIR grant H-50001-00-A000027) are also gratefully acknowledged.

\section{SUPPLEMENTARY MATERIAL}

The Supplementary Material for this article can be found online at: https://www.frontiersin.org/articles/10.3389/fmolb.2021.624061/ full\#supplementary-material.

Ferreiro, M. D., Nogales, J., Farias, G. A., Olmedilla, A., Sanjuán, J., and Gallegos, M. T. (2018). Multiple CsrA proteins control key virulence traits in Pseudomonas syringae pv. tomato DC3000. Mol. Plant Microbe Interact. 31, 525-536. doi:10.1094/MPMI-09-17-0232-R

Figueroa-Bossi, N., Schwartz, A., Guillemardet, B., D’Heygère, F., Bossi, L., and Boudvillain, M. (2014). RNA remodeling by bacterial global regulator CsrA promotes Rho-dependent transcription termination. Genes Dev. 28, 1239-1251. doi:10.1101/gad.240192.114

Heeb, S., Valverde, C., Gigot-Bonnefoy, C., and Haas, D. (2005). Role of the stress sigma factor RpoS in GacA/RsmA-controlled secondary metabolism and resistance to oxidative stress in Pseudomonas fluorescens CHA0. FEMS Microbiol. Lett. 243, 251-258. doi:10.1016/j.femsle.2004.12.008

Heroven, A. K., Böhme, K., and Dersch, P. (2012). The Csr/Rsm system of Yersinia and related pathogens: a post-transcriptional strategy for managing virulence. RNA Biol. 9, 379-391. doi:10.4161/rna.19333

Hinsa, S. M., Espinosa-Urgel, M., Ramos, J. L., and O’Toole, G. A. (2003). Transition from reversible to irreversible attachment during biofilm formation by Pseudomonas fluorescens WCS365 requires an ABC transporter and a large secreted protein. Mol. Microbiol. 49, 905-918. doi:10.1046/j.1365-2958.2003.03615.x

Hör, J., Gorski, S. A., and Vogel, J. (2018). Bacterial RNA biology on a genome scale. Mol. Cell 70, 785-799. doi:10.1016/j.molcel.2017.12.023

Huertas-Rosales, Ó., Ramos-González, M. I., and Espinosa-Urgel, M. (2016). Selfregulation and interplay of Rsm family proteins modulate the lifestyle of Pseudomonas putida. Appl. Environ. Microbiol. 82, 5673-5686. doi:10.1128/ AEM.01724-16

Huertas-Rosales, Ó., Romero, M., Heeb, S., Espinosa-Urgel, M., Cámara, M., and Ramos-González, M. I. (2017). The Pseudomonas putida CsrA/RsmA homologues negatively affect c-di-GMP pools and biofilm formation through the GGDEF/EAL response regulator CfcR. Environ. Microbiol. 19, 3551-3566. doi:10.1111/1462-2920.13848

Ishihama, A. (2010). Prokaryotic genome regulation: multifactor promoters, multitarget regulators and hierarchic networks. FEMS Microbiol. Rev. 34, 628-645. doi:10.1111/j.1574-6976.2010.00227.x

Jacob, F., and Monod, J. (1961). Genetic regulatory mechanisms in the synthesis of proteins. J. Mol. Biol. 3, 318-356. doi:10.1016/s0022-2836(61)80072-7

Janssen, K. H., Diaz, M. R., Golden, M., Graham, J. W., Sanders, W., Wolfgang, M. C., et al. (2018). Functional analyses of the RsmY and RsmZ small noncoding regulatory RNAs in Pseudomonas aeruginosa. J. Bacteriol. 200, e00736-17. doi:10.1128/JB.00736-17

Jiménez-Fernández, A., López-Sánchez, A., Calero, P., and Govantes, F. (2015). The c-di-GMP phosphodiesterase BifA regulates biofilm development in Pseudomonas putida. Environ Microbiol Rep 7, 78-84. doi:10.1111/1758-2229.12153

Kay, E., Dubuis, C., and Haas, D. (2005). Three small RNAs jointly ensure secondary metabolism and biocontrol in Pseudomonas fluorescens CHA0. Proc. Natl. Acad. Sci. U.S.A. 102, 17136-17141. doi:10.1073/pnas.0505673102 
Koch, B., Jensen, L. E., and Nybroe, O. (2001). A panel of Tn7-based vectors for insertion of the $g f p$ marker gene or for delivery of cloned DNA into Gramnegative bacteria at a neutral chromosomal site. J. Microbiol. Methods 45, 187-195. doi:10.1016/s0167-7012(01)00246-9

Langmead, B., Trapnell, C., Pop, M., and Salzberg, S. L. (2009). Ultrafast and memory-efficient alignment of short DNA sequences to the human genome. Genome Biol. 10, R25. doi:10.1186/gb-2009-10-3-r25

Lawhon, S. D., Frye, J. G., Suyemoto, M., Porwollik, S., McClelland, M., and Altier, C. (2003). Global regulation by CsrA in Salmonella typhimurium. Mol. Microbiol. 48, 1633-1645. doi:10.1046/j.1365-2958.2003.03535.x

Lennox, E. S. (1955). Transduction of linked genetic characters of the host by bacteriophage P1. Virology 1, 190-206. doi:10.1016/0042-6822(55)90016-7

Lenz, D. H., Miller, M. B., Zhu, J., Kulkarni, R. V., and Bassler, B. L. (2005). CsrA and three redundant small RNAs regulate quorum sensing in Vibrio cholerae. Mol. Microbiol. 58, 1186-1202. doi:10.1111/j.1365-2958.2005.04902.x

Martínez-Gil, M., Yousef-Coronado, F., and Espinosa-Urgel, M. (2010). LapF, the second largest Pseudomonas putida protein, contributes to plant root colonization and determines biofilm architecture. Mol. Microbiol. 77, 549-561. doi:10.1111/j.1365-2958.2010.07249.x

Matilla, M. A., Espinosa-Urgel, M., Rodríguez-Herva, J. J., Ramos, J. L., and RamosGonzález, M. I. (2007). Genomic analysis reveals the major driving forces of bacterial life in the rhizosphere. Genome Biol. 8, R179. doi:10.1186/gb-2007-8-9-r179

Matilla, M. A., Travieso, M. L., Ramos, J. L., and Ramos-González, M. I. (2011). Cyclic diguanylate turnover mediated by the sole GGDEF/EAL response regulator in Pseudomonas putida: its role in the rhizosphere and an analysis of its target processes. Environ. Microbiol. 13, 1745. doi:10.1111/j.1462-2920.2011.02499.x

Morris, E. R., Hall, G., Li, C., Heeb, S., Kulkarni, R. V., Lovelock, L., et al. (2013). Structural rearrangement in an RsmA/CsrA ortholog of Pseudomonas aeruginosa creates a dimeric RNA-binding protein, RsmN. Structure 21, 1659-1671. doi:10.1016/j.str.2013.07.007

Nilsson, M., Chiang, W. C., Fazli, M., Gjermansen, M., Givskov, M., and TolkerNielsen, T. (2011). Influence of putative exopolysaccharide genes on Pseudomonas putida KT2440 biofilm stability. Environ. Microbiol. 13, 1357-1369. doi:10.1111/j.1462-2920.2011.02447.x

Pannuri, A., Vakulskas, C. A., Zere, T., McGibbon, L. C., Edwards, A. N., Georgellis, D., et al. (2016). Circuitry linking the catabolite repression and Csr global regulatory systems of Escherichia coli. J. Bacteriol. 198, 3000-3015. doi:10.1128/JB.00454-16

Petrova, O. E., Cherny, K. E., and Sauer, K. (2014). The Pseudomonas aeruginosa diguanylate cyclase GcbA, a homolog of $P$. fluorescens GcbA, promotes initial attachment to surfaces, but not biofilm formation, via regulation of motility. J. Bacteriol. 196, 2827-2841. doi:10.1128/JB.01628-14

Ramos-González, M. I., MA, Matilla., Quesada, J. M., Ramos, J. L., and EspinosaUrgel, M. (2013). "Using genomics to unveil bacterial determinants of rhizosphere life style," in Molecular microbial ecology of the rhizosphere. Editor F. J. de Bruijn (Hoboken, NJ: John Wiley \& Sons), Vol. 1, 7-16.

Ramos-González, M. I., Travieso, M. L., Soriano, M. I., Matilla, M. A., HuertasRosales, Ó., Barrientos-Moreno, L., et al. (2016). Genetic dissection of the regulatory network associated with high c-di-GMP levels in Pseudomonas putida KT2440. Front. Microbiol. 7, 1093. doi:10.3389/fmicb.2016.01093

Regenhardt, D., Heuer, H., Heim, S., Fernández, D. U., Strömpl, C., Moore, E. R., et al. (2002). Pedigree and taxonomic credentials of Pseudomonas putida strain KT2440. Environ. Microbiol. 4, 912-915. doi:10.1046/j.1462-2920.2002.00368.x

Reimmann, C., Valverde, C., Kay, E., and Haas, D. (2005). Posttranscriptional repression of GacS/GacA-controlled genes by the RNA-binding protein RsmE acting together with RsmA in the biocontrol strain Pseudomonas fluorescens CHA0. J. Bacteriol. 187, 276-285. doi:10.1128/JB.187.1.276-285.2005

Romeo, T. (1998). Global regulation by the small RNA-binding protein CsrA and the non-coding RNA molecule CsrB. Mol. Microbiol. 29, 1321-1330. doi:10. 1046/j.1365-2958.1998.01021.x

Romeo, T., Vakulskas, C. A., and Babitzke, P. (2013). Post-transcriptional regulation on a global scale: form and function of Csr/Rsm systems. Environ. Microbiol. 15, 313-324. doi:10.1111/j.1462-2920.2012.02794.x

Romero, M., Silistre, H., Lovelock, L., Wright, V. J., Chan, K. G., Hong, K. W., et al. (2018). Genome-wide mapping of the RNA targets of the Pseudomonas aeruginosa riboregulatory protein RsmN. Nucleic Acids Res. 46, 6823-6840. doi:10.1093/nar/gky324

Sabnis, N. A., Yang, H., and Romeo, T. (1995). Pleiotropic regulation of central carbohydrate metabolism in Escherichia coli via the gene csrA. J. Biol. Chem. 270, 29096-29104. doi:10.1074/jbc.270.49.29096

Sambrook, J., and Russell, D. W. (2001). Molecular cloning: a laboratory manual. New York, NY: Cold Spring Harbor Laboratory Press, Cold Spring Harbor.

Shis, D. L., Bennett, M. R., and Igoshin, O. A. (2018). Dynamics of bacterial gene regulatory networks. Annu. Rev. Biophys. 47, 447-467. doi:10.1146/annurevbiophys-070317-032947

Sonnleitner, E., and Haas, D. (2011). Small RNAs as regulators of primary and secondary metabolism in Pseudomonas species. Appl. Microbiol. Biotechnol. 91, 63-79. doi:10.1007/s00253-011-3332-1

Sowa, S. W., Gelderman, G., Leistra, A. N., Buvanendiran, A., Lipp, S., Pitaktong, A., et al. (2017). Integrative FourD omics approach profiles the target network of the carbon storage regulatory system. Nucleic Acids Res. 45, 1673-1686. doi:10.1093/nar/gkx048

Sterzenbach, T., Nguyen, K. T., Nuccio, S. P., Winter, M. G., Vakulskas, C. A., Clegg, S., et al. (2013). A novel CsrA titration mechanism regulates fimbrial gene expression in Salmonella typhimurium. EMBO J. 32, 2872-2883. doi:10. 1038/emboj.2013.206

Vakulskas, C. A., Potts, A. H., Babitzke, P., Ahmer, B. M., and Romeo, T. (2015). Regulation of bacterial virulence by Csr (Rsm) systems. Microbiol. Mol. Biol. Rev. 79, 193-224. doi:10.1128/MMBR.00052-14

Van Assche, E., Van Puyvelde, S., Vanderleyden, J., and Steenackers, H. P. (2015). RNA-binding proteins involved in post-transcriptional regulation in bacteria. Front. Microbiol. 6, 141. doi:10.3389/fmicb.2015.00141

Winsor, G. L., Griffiths, E. J., Lo, R., Dhillon, B. K., Shay, J. A., and Brinkman, F. S. (2016). Enhanced annotations and features for comparing thousands of Pseudomonas genomes in the Pseudomonas genome database. Nucleic Acids Res. 44 (D1), D646-D653. doi:10.1093/nar/gkv1227

Xiao, Y., Nie, H., Liu, H., Chen, W., and Huang, Q. (2016). Expression of the diguanylate cyclase GcbA is regulated by FleQ in response to cyclic di-GMP in Pseudomonas putida KT2440. Environ Microbiol Rep 8, 993-1002. doi:10.1111/1758-2229.12478

Yakhnin, A. V., Baker, C. S., Vakulskas, C. A., Yakhnin, H., Berezin, I., Romeo, T., et al. (2013). CsrA activates flhDC expression by protecting flhDC mRNA from RNase E-mediated cleavage. Mol. Microbiol. 87, 851-866. doi:10.1111/mmi.12136

Yakhnin, H., Pandit, P., Petty, T. J., Baker, C. S., Romeo, T., and Babitzke, P. (2007). CsrA of Bacillus subtilis regulates translation initiation of the gene encoding the flagellin protein (hag) by blocking ribosome binding. Mol. Microbiol. 64, 1605-1620. doi:10.1111/j.1365-2958.2007.05765.x

Yang, H., Liu, M. Y., and Romeo, T. (1996). Coordinate genetic regulation of glycogen catabolism and biosynthesis in Escherichia coli via the csrA gene product. J. Bacteriol. 178, 1012-1017. doi:10.1128/jb.178.4.1012-1017.1996

Yousef-Coronado, F., Travieso, M. L., and Espinosa-Urgel, M. (2008). Different, overlapping mechanisms for colonization of abiotic and plant surfaces by Pseudomonas putida. FEMS Microbiol. Lett. 288, 118-124. doi:10.1111/j.15746968.2008.01339.x

Zhang, Y., Liu, T., Meyer, C. A., Eeckhoute, J., Johnson, D. S., Bernstein, B. E., et al. (2008). Model-based analysis of ChIP-seq (MACS). Genome Biol. 9, R137. doi:10.1186/gb-2008-9-9-r137

Conflict of Interest: The authors declare that the research was conducted in the absence of any commercial or financial relationships that could be construed as a potential conflict of interest.

Copyright (C) 2021 Huertas-Rosales, Romero, Chan, Hong, Cámara, Heeb, Barrientos-Moreno, Molina-Henares, Travieso, Ramos-González and Espinosa-Urgel. This is an open-access article distributed under the terms of the Creative Commons Attribution License (CC BY). The use, distribution or reproduction in other forums is permitted, provided the original author(s) and the copyright owner(s) are credited and that the original publication in this journal is cited, in accordance with accepted academic practice. No use, distribution or reproduction is permitted which does not comply with these terms. 